\title{
The requirement of matrix ATP for the import of precursor proteins into the mitochondrial matrix and intermembrane space
}

\author{
Rosemary A. STUART, Albrecht GRUHLER, Ida van der KLEI, Bernard GUIARD, Hans KOLL and Walter NEUPERT \\ Institut für Physiologische Chemie der Universität München, Germany
}

(Received September 22/November 22, 1993) - EJB 93 1444/6

\begin{abstract}
The role of ATP in the matrix for the import of precursor proteins into the various mitochondrial subcompartments was investigated by studying protein translocation at experimentally defined ATP levels. Proteins targeted to the matrix were neither imported or processed when matrix ATP was depleted. Import and processing of precytochrome $b_{2}\left(\mathrm{p} b_{2}\right)$, a precursor carrying a bipartite presequence, into the intermembrane space was also strongly dependent on matrix ATP. Preproteins, consisting of 220 or more residues of $\mathrm{p} b_{2}$ fused to dihydrofolate reductase, showed the same requirement for matrix ATP, whereas the import of shorter fusion proteins (up to 167 residues of p $b_{2}$ ) was largely independent of matrix ATP. For those intermembrane-space-targeted proteins that did need matrix ATP, the dependence could be relieved either by unfolding these proteins prior to import or by introducing a deletion into the mature portion of the protein thereby impairing the tight folding of the cytochrome $b_{5}$ domain.

These results suggest the following: (a) The import of matrix-targeted preproteins, in addition to a membrane potential $\Delta \Psi$, requires matrix ATP [most likely to facilitate reversible binding of mitochondrial heat-shock protein 70 (mt-Hsp70) to incoming precursors], for two steps, securing the presequence on the matrix side of the inner membrane and for the completion of translocation; (b) in the case of intermembrane-space-targeted precursors with bipartite signals, the function of ATP/mt-Hsp70 is not obligatory, as components of the intermembrane-space-sorting pathway may substitute for ATP/mt-Hsp70 function (however, if a tightly folded domain is present in the precursor, ATP/mt-Hsp 70 is indispensable); (c) unfolding on the mitochondrial surface of tightly folded segments of preproteins is facilitated by matrix-ATP/mt-Hsp 70 .
\end{abstract}

The majority of mitochondrial precursor proteins are coded for by the cell nucleus and are post-translationally imported into mitochondria along a multi-step pathway. Cytosolic proteins, especially those of the heat-shock protein 70 (Hsp70) family (SSA, in yeast), have been implicated in maintaining precursor proteins in a conformation which is translocation competent, a process which is ATP dependent $[1-3]$. Those precursors, which must insert into or translocate across the inner membrane to reach their functional location, require the presence of a membrane potential across the inner membrane to trigger the translocation of their positively charged matrix-targeting presequences [4]. Matrixtargeted proteins are translocated across the inner membrane in an extended unfolded conformation and require the presence of hydrolyzable ATP in the matrix [2, 5, 6]. Mitochondrial heat-shock protein 70 (mt-Hsp70; SSC1 in yeast), is involved in facilitating the passage of precursors across the inner membrane into the matrix [7-10]. After membrane translocation, the polypeptides are transferred from mitochondrial Hsp70 to Hsp60, where they become folded. ATP

Correspondence to $\mathrm{W}$. Neupert, Institut für Physiologische Chemie der Universität München, Goethestraße 33, D-80336 Mïnchen, Germany

Fax: +49895996270

Abbreviations. $b_{2}$, precytochrome $b_{2} ;$ mt-Hsp 70 , mitochondrial heat-shock protein $70 ; \mathrm{pF}_{1} \beta$, precursor of the $\beta$ subunit of the $\mathrm{F}_{1^{-}}$ ATP synthase. hydrolysis is required both for the release of the polypeptide chain from mt-Hsp70, as well as for the folding by and release from Hsp60 [11]. In addition, precursor proteins undergo processing by the matrix-processing peptidase to remove cleavable matrix-targeting sequences [12].

The situation with proteins targeted to the mitochondrial intermembrane space, in contrast, appears to be much more complicated. Some of these proteins in their precursor form have a bipartite signal sequence This composite signal consists of a normal matrix-targeting sequence at the $\mathrm{N}$-terminus followed by a sorting signal whose characteristics are the presence of a hydrophobic core preceded by one or more positively charged amino acid residues. The manner in which this sorting signal operates is unclear. One view is that it functions as a 'stop-transfer' signal and arrests the proteins in the inner membrane during import; the protein subsequently becomes sorted to the intermembrane space via a lateral movement in the inner membrane [13-20]. The alternative view is that these precursor proteins become imported into the matrix along the general import pathway and once in the matrix the sorting signal serves to target the export of the protein across the inner membrane. This pathway has been termed the 'conservative sorting' route as it was proposed that the export processes resemble events described for bacterial secretion and post-endosymbiotic processing, which have been maintained throughout evolution from the procaryotic ancestors of mitochondria [21-23]. A typical repre- 
sentative of this group of proteins is cytochrome $b_{2}$ of Saccharomyces cerevisiae which consists of 591 amino acid residues and has two domains, a cytochrome $b_{5}$ domain followed by a flavin-containing domain [24, 25].

Recently, following a study of the energetic requirements for the in vitro import of cytochrome $c_{1}$, it was suggested that ATP hydrolysis in the matrix and consequently mtHsp70 action, was not required for correct sorting of this precursor to the intermembrane space. Hence, it was concluded that this protein does not become translocated across the inner membrane during passage to the intermembrane space and consequently was not sorted along a conservative sorting pathway, but rather by a stop-transfer event [26]. In contrast, however, analysis of a temperature-sensitive yeast mutant of the matrix-localized mt-Hsp 70 indicated that mtHsp70 could play an important role in the import of the cytochrome $c_{1}$ and cytochrome $b_{2}$ precursors $[7,27]$.

In this present study, we examined the ATP requirement of the processes involved with the import of cytochrome $b_{2}$ and cytochrome $c_{1}$ and compared them to the energetics for import of proteins into the matrix. For import, matrix ATP requirement reflects the dependence on mt-Hsp70 [7]. Other ATP-requiring chaperones, e.g. Hsp60, do not play a role in translocation per se. Since the levels of matrix ATP could be easily manipulated, we chose to study the effect of matrixATP depletion in wild-type mitochondria. We present evidence that matrix ATP is required for sorting of some precursors to the intermembrane space. Furthermore, we demonstrate that dependence on matrix ATP is not a function of the targeting information of a precursor, and hence the selected sorting pathway, but is rather a characteristic of the precursor protein itself. More specifically, we show that the matrix ATP requirement is related to the degree of precursor folding and is required for mediating the unfolding of mature domains outside the mitochondria.

We further demonstrate that matrix-targeted precursor proteins such as the $\beta$ subunit of the $\mathrm{F}_{1}$-ATP synthase and a short cytochrome $b_{2}$-dihydrofolate reductase fusion protein in which the intermembrane space sorting signal was inactivated are neither processed nor imported into matrix-ATPdepleted mitochondria. Therefore ATP hydrolysis, reflecting the action of $\mathrm{mt}-\mathrm{Hsp} 70$, is proposed to be required for the passage of the matrix-targeting sequence into the matrix in such a fashion that it can undergo processing by the matrixlocated processing peptidase.

\section{EXPERIMENTAL PROCEDURES}

\section{Precursor proteins}

The cytochrome $b_{2}$ precursor proteins and derivatives thereof have been previously described $[24,40,28]$. The precursor $\mathrm{p} b_{2}(\Delta 135-226)$, where amino acid residues $135-226$ inclusive were deleted, encompassing the heme-binding domain of cytochrome $b_{2}$, was constructed as follows. An $E c o$ RI/HindIII DNA insert corresponding to the entire coding region of cytochrome $b_{2}$ was isolated. The resulting $2.5-\mathrm{kb}$ fragment was further digested with $M s p$ I which cuts twice in the cytochrome $b_{2}$ DNA at sites corresponding to codons 134 and 226. The resulting EcoRI-MspI and $M s p \mathrm{I}-H i n \mathrm{dIII}$ fragments were reisolated and ligated together into a pGEM4 vector which had been linearized with EcoRI and HindIII, followed by a phosphatase treatment.

The precursor proteins $\mathrm{p} c_{1}(1-34)$-dihydrofolate reductase and the $\mathrm{p} c_{1}(1-73)-$ dihydrofolate reductase were con- structed as follows. Oligonucleotide site-directed mutagenesis was performed to introduce a unique $P v u I I$ site in the Neurospora crassa cytochrome $c_{1}$ cDNA at positions corresponding to codon 34 for the $c_{1}(1-34)$-dihydrofolate reductase construct or to codon 73 for the $\mathrm{p} c_{1}(1-73)-$ dihydrofolate reductase construct, as described [29, 30]. The mutagenized cDNA was cloned into pGEM4 and cleaved with $P v u I I$. A cDNA encoding dihydrofolate reductase was also altered by site-directed oligonucleotide mutagenesis whereby an $\mathrm{NciI}$ site was introduced in the coding region corresponding to codon 6 . An $N c i \mathrm{I}-H$ indIII fragment, which contained the entire coding region of the dihydrofolate reductase with the exception of the initial five amino acids, was prepared and treated with the Klenow fragment of the Escherichia coli DNA polymerase I. The resulting insert was ligated into the two pGEM4 vectors described above to produce in-frame fusions between the cytochrome $c_{1}$ and the dihydrofolate reductase. The fusion proteins were synthesized in reticulocyte lysate following transcription of the plasmids with SP6 RNA polymerase.

\section{Induction and purification of radiolabelled precursor proteins from overexpressing $E$. coli}

Precultures in M9 minimal medium $\left(34 \mathrm{mM} \mathrm{Na}_{2} \mathrm{HPO}_{4}\right.$, $22 \mathrm{mM} \mathrm{KH} \mathrm{PO}_{4}, 8.5 \mathrm{mM} \mathrm{NaCl}, 18 \mathrm{mM} \mathrm{NH}_{4} \mathrm{Cl}, 1 \mathrm{mg} / \mathrm{l}$ vitamin $\mathrm{B}_{1}, 1 \mathrm{mM} \mathrm{MgCl}$ and $0.1 \mathrm{mM} \mathrm{CaCl}_{2}$ supplemented with $0.4 \%$ (mass/vol.) glucose and $0.2 \%$ (mass/vol.) casamino acids, were inoculated using single colonies of the appropriate E. coli strain. Cells were grown overnight at $37^{\circ} \mathrm{C}$, $200 \mathrm{rpm}$ and were diluted to $A_{585} 0.1$ into a low-sulphate me$\operatorname{dium}(50 \mu \mathrm{M} \mathrm{MgSO})_{4}$, consisting of $\mathrm{M} 9$ minimal medium supplemented with $0.4 \%$ glucose and $20 \mathrm{mg} / \mathrm{l}$ of all amino acids except cysteine and methionine. When growth slowed down due to sulphate limitation (after approximately $4-6 \mathrm{~h}$ of incubation, $A_{585}$ approximately 1.0$) 1 \mathrm{mM}$ isopropyl thio$\beta$-D-galactoside, $10 \mu \mathrm{M} \mathrm{MgSO} 4$ and $0.05 \mathrm{Ci} / 1\left[{ }^{35} \mathrm{~S} \mathrm{SO}_{4}{ }^{2-}\right.$ were added. After a further incubation for $2 \mathrm{~h}$ at $37^{\circ} \mathrm{C}$ and $200 \mathrm{rpm}$, cells were harvested and used to isolate inclusion bodies as previously described [31]. The inclusion bodies were dissolved in $8 \mathrm{M}$ urea, $100 \mathrm{mM}$ dithiothreitol, $20 \mathrm{mM}$ Hepes, pH 7.4 (buffer A) and aliquots were stored at $-20^{\circ} \mathrm{C}$. Prior to import experiments, the proteins were diluted in freshly prepared buffer $A$ and added to the import assay at a final concentration of $0.25 \mu \mathrm{g} / \mathrm{ml}$ and at a final urea concentration of $160 \mathrm{mM}$.

\section{Import of precursor proteins into mitochondria}

Wild-type S. cerevisiae (D273-10B) cells were grown overnight in lactate medium and cells were harvested at $A_{578}$ $1-1.5$. Mitochondria were isolated as previously described $[40,32]$.

Precursor proteins, where indicated, were synthesized in the presence of $\left[{ }^{35} \mathrm{~S}\right]$ methionine by coupled transcription translation in reticulocyte lysate (Amersham) as described before $[29,30,33,34]$. Postribosomal supernatants were prepared and supplemented as described previously [35]. Import mixtures $(200 \mu \mathrm{l})$ usually contained $2 \mathrm{mM}$ NADH, $2 \mu \mathrm{l}$ ATP regenerating system (containing $0.2 \mathrm{mg} / \mathrm{ml}$ creatine phosphokinase, $100 \mathrm{mM}$ creatine phosphate, $25 \mathrm{mM}$ ATP, $25 \mathrm{mM}$ $\mathrm{MgCl}_{2}$ ), 5\% (by vol.) reticulocyte lysate in 3\% (mass/vol.) bovine serum albumin, $50 \mathrm{mM}$ Hepes, $\mathrm{pH} 7.2,0.5 \mathrm{M}$ sorbitol, $80 \mathrm{mM} \mathrm{KCl}, 10 \mathrm{mM} \mathrm{MgOAc}, 2 \mathrm{mM}$ potassium phosphate, $2.5 \mathrm{mM}$ EDTA, $1 \mathrm{mM} \mathrm{MnCl}_{2}$ (buffer $\mathrm{B}$ ). The final 
concentration of mitochondria in the import reaction was $0.2 \mathrm{mg}$ protein $/ \mathrm{ml}$. Import was performed at $25^{\circ} \mathrm{C}$ for the times indicated. Following the import incubation, samples were placed on ice and divided into two aliquots and were diluted fourfold by the addition of ice-cold $0.6 \mathrm{M}$ sorbitol, $50 \mathrm{mM}$ Hepes, $80 \mathrm{mM} \mathrm{KCl}, \mathrm{pH} 7.2$ (buffer C). One of the aliquots received proteinase $\mathrm{K}(100 \mu \mathrm{g} / \mathrm{ml})$ and samples were left on ice for $30 \mathrm{~min}$. Following the addition of phenylmethylsulphonyl fluoride $(2 \mathrm{mM})$, mitochondria were again isolated by centrifugation $\left(15 \mathrm{~min}, 15000 \mathrm{rpm}, 4^{\circ} \mathrm{C}\right.$, JA-18 Beckman rotor). The mitochondrial pellet and Eppendorf tube were washed by the addition of $400 \mu \mathrm{l}$ buffer $\mathrm{C}$ containing $1 \mathrm{mM}$ phenylmethylsulphonyl fluoride, without suspending the mitochondrial pellet, and samples were centrifuged again as described before. The samples were analysed by SDS/PAGE and the resulting fluorographs are presented.

Precursor proteins were synthesized in reticulocyte lysate and precipitated with ammonium sulfate (66\% saturation) for $30 \mathrm{~min}$ at $0^{\circ} \mathrm{C}$, pelleted by centrifugation $(12000 \mathrm{rpm}$, $12 \mathrm{~min}, 2^{\circ} \mathrm{C}, \mathrm{JA}-18 \mathrm{Beckman}$ rotor) and dissolved in buffer A. For import, urea-denatured precursor was diluted 50 -fold directly into the import sample containing mitochondria, so that the final concentration of urea was $160 \mathrm{mM}$. Amounts of the urea-denatured precursor employed were equivalent to those used in the import experiments with non-denatured protein.

\section{Reduction of matrix ATP levels}

Mitochondria ( $40 \mu \mathrm{g}$ protein) were incubated with buffer B $(195 \mu \mathrm{l})$ for $3 \mathrm{~min}$ at $25^{\circ} \mathrm{C}$ to promote turn-over of preexisting endogenous ATP. Oligomycin was added to a final concentration of $20 \mu \mathrm{M}$ [final ethanol concentration of $0.5 \%$ (by vol.)]. Samples were incubated for a further $3 \mathrm{~min}$ at $25^{\circ} \mathrm{C}$ and carboxyatractyloside was added $(5 \mu \mathrm{M})$; the incubation was continued for a further $3 \mathrm{~min}$. NADH was added ( $2 \mathrm{mM}$ ) and the incubation was continued for $3 \mathrm{~min}$ at $25^{\circ} \mathrm{C}$ before adding $\operatorname{MgATP}(2 \mathrm{mM})$ in the form of an ATP regenerating system, to maintain high levels of external ATP. Samples were kept at $25^{\circ} \mathrm{C}$ for a further $3 \mathrm{~min}$ and were transferred to ice for $2 \mathrm{~min}$ prior to the addition of the reticulocyte lysate containing the radiolabelled precursor proteins. Control samples were treated in an identical manner, and in parallel to those for reduced ATP described above, including the addition of carboxyatractyloside and with the exception that oligomycin was omitted.

\section{Miscellaneous}

The following procedures were performed according to published methods: protein determination [36]; SDS/PAGE [37]; fluorography [22]. Isolation of DNA fragments and oligonucleotides, plasmid preparations, ligations, phosphorylation and dephosphorylation of DNA and transformation were performed essentially as previously described [38].

\section{RESULTS}

\section{Proteins targeted to the matrix do not reach the matrix space when ATP in the matrix is depleted}

To address the energetic requirements for the import of precursor proteins into the matrix, we studied the effect of depleting the ATP in the matrix space. To this end, it was necessary to develop conditions which resulted in the effi- cient reduction of ATP levels. We established a novel and simple protocol to reduce matrix ATP levels. Isolated mitochondria were incubated initially with import buffer in the absence of respiratory-chain substrates, to promote turnover of pre-existing ATP; oligomycin was subsequently added. Oligomycin, a specific inhibitor of the ATP synthase, prevents new production of ATP. Following this treatment, carboxyatractyloside was added which blocks the transport of exogenously added ATP into the mitochondrial matrix at the level of the ADP/ATP carrier. The import of the majority of precursor proteins requires ATP hydrolysis in the cytosol and ATP was therefore added to the import reaction in the form of a regenerating system to maintain high levels of ATP outside the mitochondria.

Measurements of the mitochondrial ATP levels were performed to indicate the extent of ATP depletion (Fig. 1A). When the internal concentrations of ATP were adjusted to normal levels of approximately $1.4 \mathrm{mM}$ [39], by an incubation with NADH and ATP in the absence of carboxyatractyloside (i.e. when entry of ATP from the cytosol was not blocked; Fig. 1A, lane 1), efficient preprotein import took place. As an example, this is shown for $\mathrm{pSu} 9$-dihydrofolate reductase, a fusion protein consisting of the presequence of subunit 9 of the ATP synthase and mouse cytosolic dihydrofolate reductase. This precursor has an unusually long presequence of 67 amino acid residues that becomes processed by the matrix-processing peptidase in two steps. When mitochondria were initially diluted into import buffer which contained carboxyatractyloside to minimize further leakage of pre-existing ATP or ADP, and subsequently incubated with $\mathrm{NADH}, \mathrm{ATP}$ levels corresponding to $700 \mu \mathrm{M}$ were measured (lane 2). This indicates that isolated mitochondria following subcellular fractionation contained subnormal ATP levels probably because of leakage during the isolation. However, this level was sufficient to support efficient import of precursor proteins into the matrix. Mitochondria which had undergone a mock treatment for ATP depletion, i.e. were incubated without oligomycin and carboxyatractyloside for an initial period of $6 \mathrm{~min}$, suffered a further loss of ATP (final concentration approximately $280 \mu \mathrm{M}$; Fig. 1 A, lane 4). This rather low ATP level was still sufficient to promote import with the same efficiency as the higher levels described before (Fig. 1B, lane 4 versus lanes 1 and 2). Mitochondria which had been treated according to the depletion protocol (first with oligomycin and secondly with carboxyatractyloside) as introduced above had significantly reduced ATP levels of $80-100 \mu \mathrm{M}$ (Fig. 1 A, lane 5). Import of the precursor under these specific conditions was almost completely blocked; only trace amounts of intermediate-sized precursor were observed (Fig. 1B, lane 5). If carboxyatractyloside was present prior the addition of oligomycin a somewhat higher ATP level was observed (approximately $150 \mu \mathrm{M}$ ), probably because under the latter condition the loss of adenine nucleotides was lower (Fig. 1 A, lane 3); import was still very inefficient and only intermediate-sized precursor was observed in a considerable amount (Fig. 1B, lane 3).

Matrix-ATP depletion lead also to a block of import of an authentic precursor protein, the $\beta$ subunit of the $\mathrm{F}_{1}$-ATP synthase $\left(\mathrm{pF}_{1} \beta\right.$; Fig. 2A). Furthermore, when chemical amounts of a precursor were imported, ATP depletion resulted in a complete inhibition of translocation into the matrix (Fig. 2B). p $b_{2}(167) \Delta 19$-dihydrofolate reductase, a fusion protein consisting of the first 167 amino acids of cytochrome $b_{2}$ and dihydrofolate reductase, was expressed in $E$. coli, purified, dissolved in $8 \mathrm{M}$ urea and added to isolated 
A

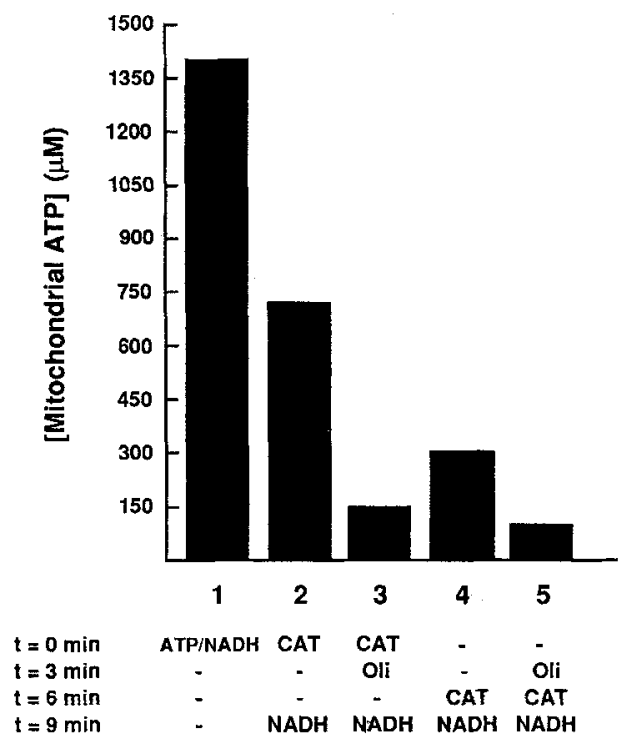

B

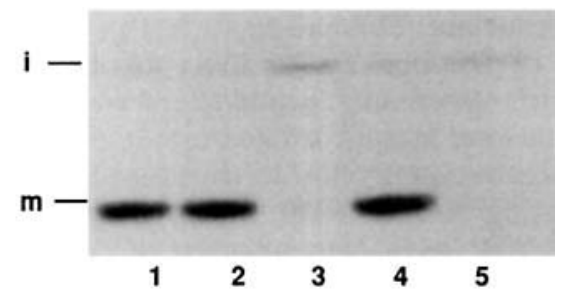

Fig. 1. Inhibition of import of matrix-targeted precursor protein is correlated with the depletion of mitochondrial ATP levels. Mitochondria were diluted to a final concentration of $200 \mu \mathrm{g} / \mathrm{ml}$ in buffer B containing either no additions (lanes 4 and 5), or carboxyatractyloside $(5 \mu \mathrm{M})$ (lanes 2 and 3 ) or NADH $(2 \mathrm{mM})$ plus an ATPregenerating system (lane 1). Following a 3 min incubation at $25^{\circ} \mathrm{C}$, either oligomycin (lanes 3 and 5) or ethanol (lanes 1, 2, and 4) were added and samples were incubated for a further $3 \mathrm{~min}$ at $25^{\circ} \mathrm{C}$. Carboxyatractyloside was added (lanes 4 and 5) and incubations were continued for a further $3 \mathrm{~min}$ prior to the addition of NADH ( $2 \mathrm{mM}$; lanes $2-5)$. The samples were then used for (A) quantifying ATP or (B) import studies. (A) Following a further 2 min at $25^{\circ} \mathrm{C}$, samples were loaded onto silicon oil AR200, $235 \mathrm{mPa} \cdot \mathrm{s}$ (Fluka) and pelleted by centrifugation for $2 \mathrm{~min}$ in an Eppendorf centrifuge. The upper surface of the oil was washed with $1 \mathrm{ml} \mathrm{SHKCl}$ buffer $\mathrm{C}$ and the mitochondrial pellets were extracted with 7\% (by vol.) perchloric acid. The protein precipitate was separated by centrifugation and the supernatant was neutralized following the addition of 0.5 vol. $0.2 \mathrm{M}$ Mops, $2 \mathrm{M} \mathrm{KOH}$. The sample was centrifuged again and an aliquot of the supernatant was used for ATP measurement using the luciferase assay [48]. (B) Following the addition of NADH, ATP ( $2 \mathrm{mM}$ ) was added to all samples, and incubated for a further $3 \mathrm{~min}$ prior to the addition of reticulocyte lysate $(1 \%)$ containing $\left.{ }^{{ }^{35} \mathrm{~S}}\right]$ methionine-labelled precursor of $\mathrm{Su} 9$-dihydrofolate reductase. Import was performed for $2.5 \mathrm{~min}$ at $25^{\circ} \mathrm{C}$ and samples were placed on ice and diluted fourfold with buffer $\mathrm{C}$ and treated with proteinase $\mathrm{K}(60 \mu \mathrm{g} / \mathrm{ml})$ for $30 \mathrm{~min}$ on ice. Samples were processed as described in the Experimental Procedures section. i, intermediate; $m$, mature; Oli, oligomycin; CAT, carboxyatractyloside.

mitochondria in buffer $B$. In this ' $\Delta 19$ ' construct the residues $47-65$ of the bipartite presequence were removed, leading to the inactivation of the intermembrane space sorting signal; these 19 residues include the three positive charges Arg-LysArg, and part of the hydrophobic core of the signal sequence,
$\mathbf{A}$

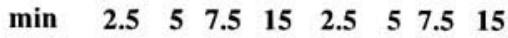

- PK

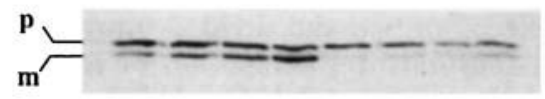

+ PK

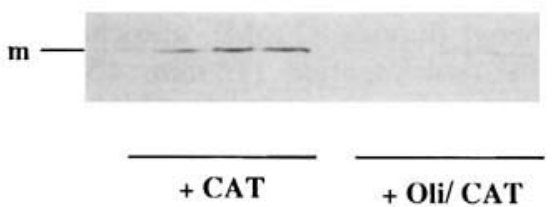

B

$\begin{array}{lllllllll}\min & 2.5 & 5 & 7.5 & 15 & 2.5 & 5 & 7.5 & 15\end{array}$

- PK

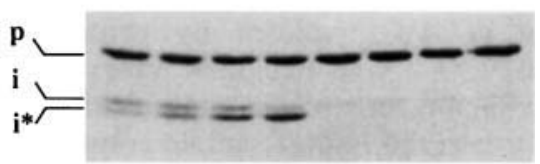

$+\mathbf{P K}$

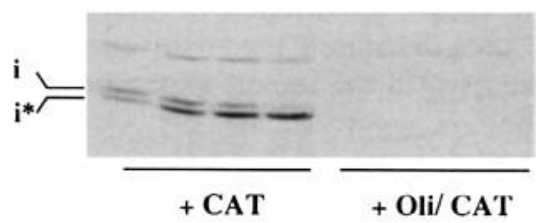

Fig. 2. Matrix-targeted precursor proteins require matrix ATP for both processing and import. The precursor protein $\mathrm{pF}_{1} \beta$-ATP synthase (A) was synthesized in reticulocyte lysate and imported into control (lanes 1-4) and ATP-depleted mitochondria (lanes 58 ) as described in the legend of Fig. 2. The precursor to $\mathrm{p} b_{2}(167) \Delta 19$-dihydrofolate reductase was expressed in $E$. coli in the presence of $\left.{ }^{35} \mathrm{~S}\right]$ sulphate and purified. Import of the urea-denatured precursor was performed into control and ATP-depleted mitochondria (B). Following import, samples were placed on ice, one half of each sample was treated with proteinase $\mathrm{K}(+\mathrm{PK})$ the other did not receive this treatment $(-P K)$. All samples were processed as described in the Experimental Procedures section. $i^{*}$, degradation product of $i$ form; $i$, intermediate; $p$, precursor; Oli, oligomycin; CAT, carboxyatractyloside.

both features being essential for correct intermembrane space sorting in mitochondria $[40,41]$. In the presence of matrix ATP, $\mathrm{p} b_{2}(167) 419$-dihydrofolate reductase was imported and processed to intermediate-sized forms, $\mathrm{i}$ and $\mathrm{i}^{*}$ [40] (Fig. 2B, lanes 1-4). Processing by the matrix-processing peptidase, as well as import of this precursor protein, however, were strongly inhibited by reducing matrix-ATP levels with oligomycin and carboxyatractyloside (Fig. 2B, lanes 58).

A major role of matrix ATP can be assigned to its requirement for mitochondrial $\mathrm{Hsp} 70$ function which in turn has been shown to fulfill an essential role in the transfer of preproteins across both membranes of the mitochondrion. The $K_{\mathrm{m}}$ of mt-Hsp70 has not been determined, however, that of the closest homolog, DnaK from E. coli is approximately $20 \mu \mathrm{M}$ [42]. The levels of ATP in the ATP-depleted mitochondria shown in this study to be deficient in import are higher. It must be considered, however, that these ATP levels measured include both free and bound ATP. A significant portion of matrix ATP is known to be tightly bound to protein and consequently not available for $\mathrm{mt}-\mathrm{Hsp} 70$. For example, $F_{1}$-ATPase contains six ATP-binding sites three of which are 


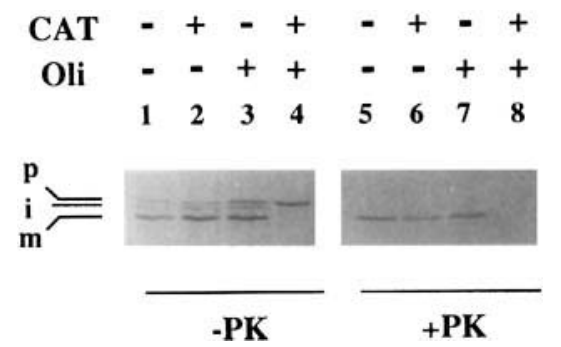

Fig. 3. Import of cytochrome $b_{2}$ into mitochondria requires matrix ATP. Mitochondria were incubated in order to reduce the levels of matrix ATP as described in the Experimental Procedures section. ${ }^{35}$ S]Methionine-labelled cytochrome $b_{2}$ precursor synthesized in reticulocyte lysate was imported for $5 \mathrm{~min}$ at $25^{\circ} \mathrm{C}$. Import was performed in the presence of external ATP, and the various samples were supplemented as follows: lanes $1,2,5$ and 6 were mock treated; lanes $3,4,7$ and 8 received $20 \mu \mathrm{M}$ oligomycin (Oli). $5 \mu \mathrm{M}$ carboxyatractyloside (CAT) was added to samples 2, 4, 6 and 8 . After import, samples were cooled on ice, diluted with buffer $\mathrm{C}$ and divided in half. One half was treated with $100 \mu \mathrm{g} / \mathrm{ml}$ proteinase $\mathrm{K}$ $(+\mathrm{PK})$, the other was mock treated ( $-\mathrm{PK})$, and samples were processed as described in the Experimental Procedures section. p, precursor; i, intermediate; $m$, mature.

present on $\alpha$ subunits with an apparent $K_{\mathrm{d}}$ in the nanomolar range [43]. On the basis of $F_{1}$-ATPase representing approximately $1-1.5 \%$ of total mitochondrial protein [44], approximately $70-100 \mu \mathrm{M}$ ATP is tightly bound and hence unavailable for Hsp 70 function. This shows that under our depletion conditions, the amount of matrix ATP must be extremely low. Although it is not possible to precisely quantitate these minor residual amounts of ATP in the matrix which are available for Hsp70 function, it is clear that ATP under the most stringent depletion conditions applied in this study will be limiting for Hsp70 function.

Taken together, these results suggest that in the absence of ATP hydrolysis and presumably mt-Hsp70 function, not only the import of the protein is inhibited, but also it appears that presequences are not stably translocated across the inner membrane. This would infer that mt-Hsp70/ATP has a function in shifting the equilibrium so as to arrest the presequence on the matrix side of the inner membrane in a topology which allows access to and cleavage by matrix-processing peptidase.

\section{Import of cytochrome $b_{2}$ requires matrix ATP}

To analyze the role of $\mathrm{mt}-\mathrm{Hsp} 70$ and the energetic requirements of the sorting events involved with intermembrane space proteins, we investigated the effects of depletion of matrix ATP on the sorting of cytochrome $b_{2}$. Import and processing of cytochrome $b_{2}$ to its intermediate and maturesized forms occurred in both the mock-treated sample (Fig. 3, lanes 1 and 5) and in the samples treated with either oligomycin (lanes 2 and 6) or carboxyatractyloside (lanes 3 and 7) alone. This demonstrated that neither of these substances had a non-specific effect on the import of cytochrome $b_{2}$. In contrast, if import was performed in the presence of both oligomycin and carboxyatractyloside, processing of the precursor form and import were strongly inhibited (lanes 4 and 8). We conclude that the reduction of the amount of matrix ATP to levels too low to support import of precursors into the matrix also inhibits import of cytochrome $b_{2}$ and therefore that matrix ATP is required for import of cytochrome $b_{2}$ into the intermembrane space. Since the inactivation of mitochondria $\begin{array}{lllllllll}2.5 & 5 & 7.5 & 15 & 2.5 & 5 & 7.5 & 15 & \mathrm{~min}\end{array}$

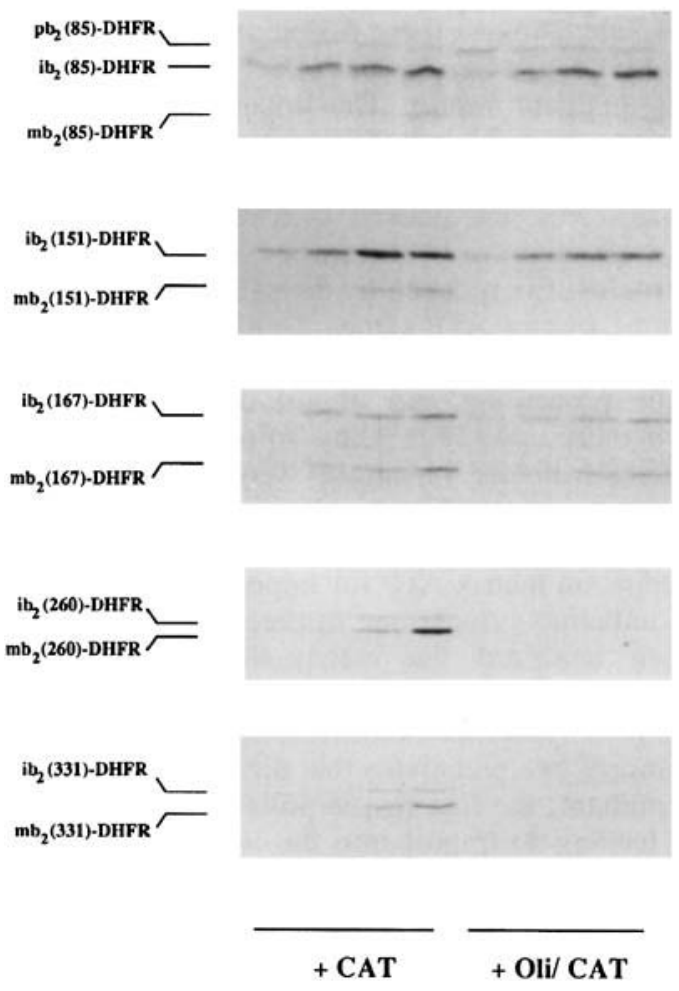

Fig. 4. Import of cytochrome $b_{2}$ fusion proteins requires varying amounts of matrix ATP. Reticulocyte lysates containing $\left[{ }^{35}\right.$ S]methionine-labelled precursors of cytochrome $b_{2}(85)-$, $b_{2}(151)-, b_{2}(167)-, b_{2}(260)-, b_{2}(331)$-dihydrofolate reductase (as indicated) were incubated with mitochondria $(20 \mu \mathrm{g} / 100 \mu \mathrm{l}$ sample) which had been treated with carboxyatractyloside alone, (lanes $1-$ 4) or treated to reduce levels of matrix ATP with carboxyatractyloside plus oligomycin, (lanes 5-8) as described in the Experimental Procedures section. Import was performed at $25^{\circ} \mathrm{C}$ for the time periods indicated, after which samples were treated with proteinase $\mathrm{K}$ $(100 \mu \mathrm{g} / \mathrm{ml})$ as described before. DHFR, dihydrofolate reductase; Oli, oligomycin; CAT, carboxyatractyloside.

of Hsp70 in temperature-sensitive mutants had the same inhibitory effect on cytochrome $b_{2}$ import as matrix-ATP depletion ([49], Stuart, R. A. and Neupert, W., unpublished results) we suggest that Hsp70/ATP binding to the cytochrome $b_{2}$ precursor in the matrix is essential for import into the intermembrane space.

\section{The matrix-ATP requirement of $\mathrm{p} b_{2}$-dihydrofolate reductase fusion proteins varies strongly depending on the size of the cytochrome $b_{2}$ moiety}

We then studied the effect of reducing matrix-ATP levels in this manner on the import of a series of cytochrome $b_{2}-$ dihydrofolate reductase fusion proteins. These fusion proteins were composed of $\mathrm{N}$-terminal residues of pre-cytochrome $b_{2}$ (positions $1-85$ up to positions $1-331$ ) that were joined to the entire mouse cytosolic dihydrofolate reductase enzyme [40]. Thus, all these fusion proteins contain identical mitochondrial targeting and sorting information, namely the cytochrome $b_{2}$ bipartite presequence, and vary only in the lengths of their mature domains. The kinetics of import of each of these fusion proteins were tested under conditions of high and reduced matrix ATP (Fig. 4). The various fusion 
proteins were imported and processed to both intermediate and mature forms in the presence of high matrix ATP (Fig. 4, lanes $1-4$ ). Interestingly, these fusion proteins could be classified into two categories by the effect of reducing matrixATP levels on their import. The import of the shorter fusion proteins, namely $\mathrm{p} b_{2}(85)$-dihydrofolate reductase, $\mathrm{p} b_{2}(151)$-dihydrofolate reductase and $\mathrm{p} b_{2}(167)$-dihydrofolate reductase, was not blocked as a result of the previous incubation with oligomycin and carboxyatractyloside. Import of these proteins was reduced by $20-40 \%$ in the absence of high levels of matrix ATP (lanes 5-8), suggesting that an ATP-mediated process was limiting for efficient import. In contrast, the processing and import of the longer fusion proteins, namely $\mathrm{p} b_{2}(260)$-dihydrofolate reductase and $\mathrm{p} b_{2}(331)$-dihydrofolate reductase were severely inhibited under conditions of reduced levels of matrix ATP (Fig. 4, lanes 1-4 versus lanes 5-8). Thus the dependence of these fusion proteins on matrix ATP for import resembles that displayed by authentic cytochrome $b_{2}$ precursor.

We then analyzed the matrix-ATP requirements of the import of $\mathrm{p} b_{2}(220)$-dihydrofolate reductase and $\mathrm{p} b_{2}(220) \Delta 19$-dihydrofolate reductase in parallel reactions to directly compare two precursors that differed only in the sorting-signal domain; the first fusion protein had an intact sorting signal leading to import into the intermembrane space, the latter had a defective sorting signal leading to transport into the matrix. Control mitochondria received neither oligomycin nor carboxyatractyloside. A previous treatment with oligomycin alone was sufficient to cause a significant reduction in the import of $\mathrm{p} b_{2}(220) \Delta 19$-dihydrofolate reductase, the matrix-targeted precursor, and in the presence of $0.75 \mu \mathrm{M}$ carboxyatractyloside, import was clearly inhibited. In contrast, import of $\mathrm{p} b_{2}(220)$-dihydrofolate reductase was relatively unaffected by the presence of oligomycin (import $85 \%$ of control) and complete inhibition of import required the presence of carboxyatractyloside concentrations higher than $2 \mu \mathrm{M}$ (Fig. 5). Apparently, inhibition of the ATP synthase by oligomycin caused a significant reduction in matrix ATP levels, despite the fact that import of external ATP via the ADP/ ATP carrier could still occur. Clearly the resulting ATP levels are limiting for the import of matrix-targeted proteins, but remain sufficient for that of intermembrane-space-destined proteins. This result underscores the conclusion that import of matrix-targeted precursors does not occur at low micromolar ATP concentrations which still allow import of intermembrane space-targeted preproteins.

To summarize, cytochrome $b_{2}$ fusion proteins of different lengths display different requirements for matrix ATP for import to the intermembrane space. Thus the lack of apparent dependence on matrix ATP for import does not reflect the import and sorting pathway taken by these fusion proteins as they all have the same mitochondrial sorting information and identical proteins possessing different sorting signals show drastic differences in their matrix-ATP requirements.

\section{Fusion proteins containing different segments of cytochrome $c_{1}$ precursor display differences in their matrix-ATP requirements}

In addition to studying the matrix-ATP requirements for cytochrome- $b_{2}$-derived dihydrofolate reductase fusion proteins, we also addressed the effect of these matrix ATP-depletion treatments on two cytochrome- $c_{1}$-derived fusion proteins. The import of $\mathrm{p} c_{1}(1-34)$-dihydrofolate reductase, a fusion protein which consists only of the matrix-targeting

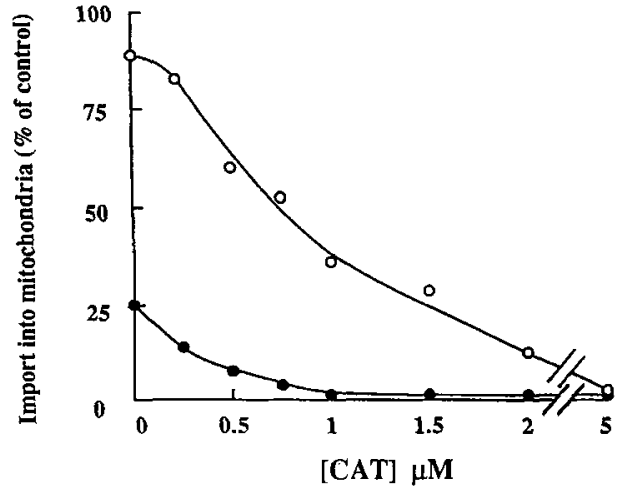

Fig. 5. Matrix-targeted precursor proteins require more matrix ATP for import than their intermembrane-space-targeted counterparts. The preproteins $\mathrm{p} b_{2}(220) \Delta 19$ dihydrofolate reductase (O) and $\mathrm{p} b_{2}(220)$-dihydrofolate reductase $(O)$ were synthesized in reticulocyte lysate in the presence of $\left[{ }^{35} \mathrm{~S}\right]$ methionine and were imported either into control mitochondria or into mitochondria which in the presence of oligomycin, had been treated with increasing amounts of carboxyatractyloside (CAT). Import was performed for $5 \mathrm{~min}$ at $25^{\circ} \mathrm{C}$, after which samples were cooled on ice, diluted with buffer $\mathrm{C}$ and treated with proteinase $\mathrm{K}$. Samples were subjected to SDS/PAGE and fluorography. Imported $\mathrm{i}-+\mathrm{m}-b_{2}(220)-$ dihydrofolate reductase and $\mathrm{i}-b_{2}(220) \Delta 19$-dihydrofolate reductase were quantified by laser densitometry. The results obtained are expressed relative to the control (no oligomycin, no carboxyatractyloside) which was set to $100 \%$.

domain of the cytochrome $c_{1}$ bipartite presequence fused to dihydrofolate reductase and hence a matrix-targeted precursor protein, was clearly dependent on the presence of matrix ATP (Fig. 6A). This result is consistent with those findings for the import of the other matrix-targeted fusion proteins in this study, $\mathrm{p} b_{2}(167) \Delta 19$-dihydrofolate reductase, $\mathrm{pF}_{1} \beta$ ATPase and pSu9(1-69)-dihydrofolate reductase. However, the import of the intermembrane-space-targeted precursor protein, $\mathrm{p} c_{1}(1-73)$-dihydrofolate reductase, containing the complete cytochrome $c_{1}$ bipartite presequence, was not inhibited under these matrix-ATP depletion conditions, however, a significant reduction (up to $40 \%$ ) in import was observed under reduced matrix-ATP levels (Fig. 6B). Similar results were also obtained for the import of the authentic cytochrome $c_{1}$ precursor (data not shown). A rather weak dependence on matrix-ATP levels of the import of yeast cytochrome $c_{1}$ and a $c_{1}(1-64)$-dihydrofolate reductase fusion protein, has been described recently [26]. In our experiments, however, there was a consistent reduction of import by $30-$ $50 \%$ in matrix-ATP-depleted mitochondria. One possible explanation for the difference is varying extents of the matrixATP depletion following the different pretreatments.

\section{Requirement for matrix ATP reflects the folding state of the mature portion of the precursor}

The observed effects of matrix-ATP depletion on the series of cytochrome $b_{2}$ fusion proteins, would initially suggest that the smaller the fusion protein was, the less was the requirement for high levels of matrix ATP for its import. The following results, however, suggest that it is the degree of folding of the precursor protein which is to be imported, rather than its size, which is decisive for an apparent matrixATP requirement.

Two independent approaches were undertaken to ask whether the folding of the mature cytochrome $b_{2}$ region has 
A

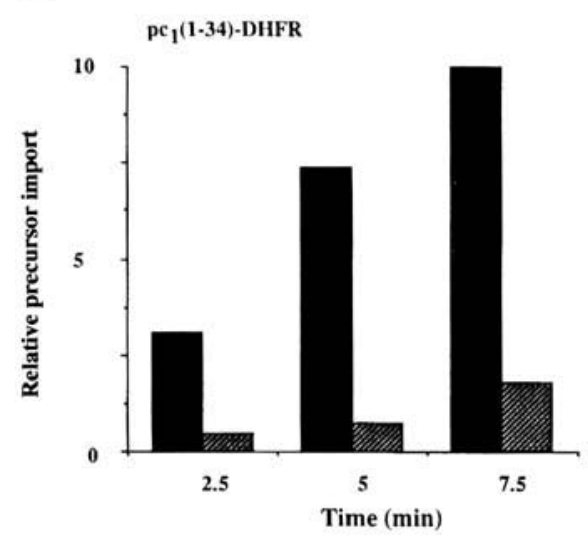

B

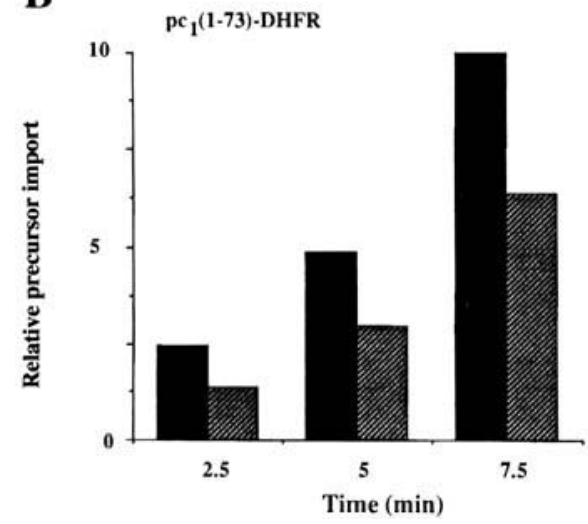

Fig. 6. Two different cytochrome $c_{1}$-derived fusion proteins display varying matrix-ATP requirements for import. The precursors of the $\mathrm{p} c_{1}(1-34)-$ dihydrofolate reductase $(\mathrm{A})$ and $\mathrm{p} c_{1}(1-73)-$ dihydrofolate reductase (B) were synthesized in reticulocyte lysate in the presence of $\left[{ }^{35} \mathrm{~S}\right]$ methionine and were imported either into control mitochondria ( $\square$ ) or into ATP-depleted mitochondria $(E \Delta)$ at $25^{\circ} \mathrm{C}$ for the times indicated. Import was assessed following proteinase $\mathrm{K}$ treatment as described in the Experimental Procedures section. Samples were analysed by SDS/PAGE and imported $m-c_{1}(1-34)-$ dihydrofolate reductase (mature size) and $\mathrm{i}-c_{1}(1-73)$ - dihydrofolate reductase (intermediate size, construct does not get cleaved to mature size) were quantified by subsequent laser densitometry of resulting fluorographs.

an influence on the ATP requirement in the matrix for import. The first involved unfolding of the precursor protein $\mathrm{p} b_{2}(331)$-dihydrofolate reductase by treatment with $8 \mathrm{M}$ urea prior to import into mitochondria (Fig. 7). Urea-denatured precursor could be imported into mitochondria which had previously been treated with oligomycin and carboxyatractyloside. The level of import into mitochondria at high levels of ATP was slightly greater, however, suggesting that unfolding of the precursor could not completely circumvent the matrix-ATP requirement. Similar results were obtained with the $\mathrm{p} b_{2}(220)$-dihydrofolate reductase and $\mathrm{p} b_{2}(260)$ dihydrofolate reductase fusion proteins (data not shown).

Cytochrome $b_{2}$, a lactate dehydrogenase, contains both heme and flavin as prosthetic groups. It has been shown that the first approximately 100 residues of the mature polypeptide chain form a tightly folded structure which constitutes the cytochrome $b_{5}$ domain [25]. This corresponds to approximately residues $81-181$ of the uncleaved precursor protein. Thus fusion proteins $\mathrm{p} b_{2}(167)$-dihydrofolate reductase and smaller fusion proteins may not contain an intact folded cyto-

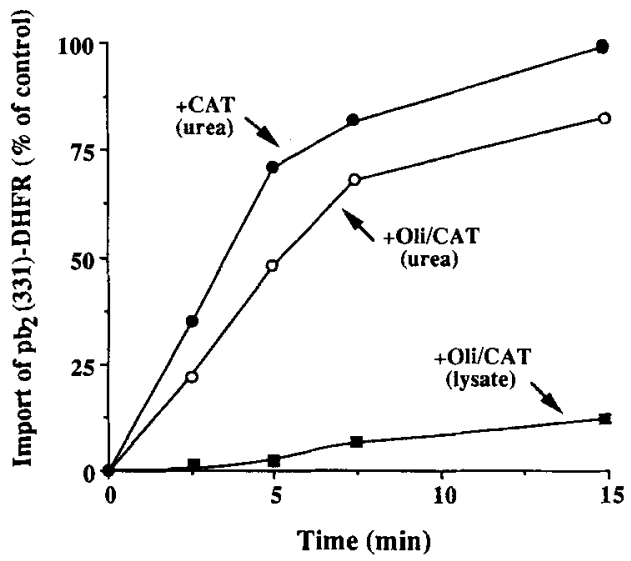

Fig. 7. Urea denaturation of $\mathrm{pb}_{2}(331)$-dihydrofolate reductase largely relieves the dependence on matrix ATP for import. Reticulocyte synthesized precursor $\mathrm{p} b_{2}(331)$-dihydrofolate reductase was ammonium-sulphate precipitated and denatured in $8 \mathrm{M}$ urea prior to import as described in the Experimental Procedures section. The precursor was imported into control mitochondria (O), + CAT(urea), or into ATP-depleted mitochondria $(\mathrm{O})$, +Oli/CAT(urea), at $25^{\circ} \mathrm{C}$ for the times indicated as described in the legend of Fig. 2. After import, samples were treated with proteinase $\mathrm{K}$ to assess for translocation into a protease-protected location, as described in the legend of Fig. 1. Samples were subjected to SDS/PAGE and fluorography. Imported $\mathrm{i}-+\mathrm{m}-b_{2}(331)-$ dihydrofolate reductase was quantified following laser densitometry and the level of import after $15 \mathrm{~min}$ in the control mitochondria was set to $100 \%$. In addition, $\mathrm{p} b_{2}(331)$-dihydrofolate reductase synthesized in reticulocyte lysate was also imported into ATP-depleted mitochondria without prior urea denaturation for comparison ( $\mathbf{0}),+\mathrm{Oli} / \mathrm{CAT}$ (lysate), and the results are expressed relative to the import of the equivalent precursor into control mitochondria after $15 \mathrm{~min}$ of incubation. CAT, carboxyatractyloside; DHFR, dihydrofolate reductase; Oli, oligomycin.

chrome $b_{5}$ domain, whilst the fusion protein $\mathrm{p} b_{2}(220)-$ dihydrofolate reductase and larger fusion proteins could. We investigated whether it was due to the presence of this folded domain in the mature sequence, rather than the absolute length of the precursor protein, which determined if matrix ATP was required for import of these precursors. A derivative of precytochrome $b_{2}$ was constructed, precytochrome $b_{2}(\Delta 135-226)$ where 91 residues had been removed. This precursor protein was translated in reticulocyte lysate and could be imported into mitochondria both in the presence or absence of high matrix-ATP levels (Fig. 8). Although this precursor is in fact larger than the $\mathrm{p} b_{2}(260)$-dihydrofolate reductase, it no longer displayed the apparent requirement for matrix ATP.

Together, these results suggest that matrix ATP is necessary for the unfolding of a domain which has a tendency to fold into a stable structure outside the mitochondria. Furthermore, it appears that the efficiency of processing of the intermediate cytochrome $b_{2}$ to its mature size form by the innermembrane protease 1 [45] is also influenced by the absence of the cytochrome $b_{5}$ domain. After $15 \mathrm{~min}$ of import, the majority of the precursor protein was still present as an intermediate species, in contrast to the authentic cytochrome $b_{2}$ which was almost completely processed to the mature species after 5 min of import (Fig. 3, lane 1). The retarded processing by inner-membrane protease 1 was also observed for the fusion proteins $\mathrm{p} b_{2}(85)$-dihydrofolate reductase, $\mathrm{p} b_{2}(151)$-dihydrofolate reductase and $\mathrm{p} b_{2}(167)$-dihydrofolate reductase, suggesting also that efficient inner-membrane 


$$
\mathrm{pb}_{2}(\Delta \text { 135-226) }
$$

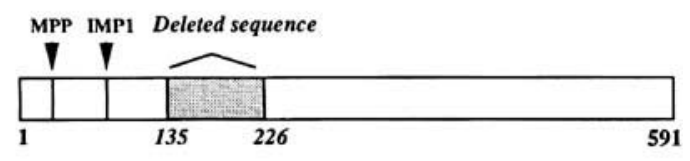

- PK

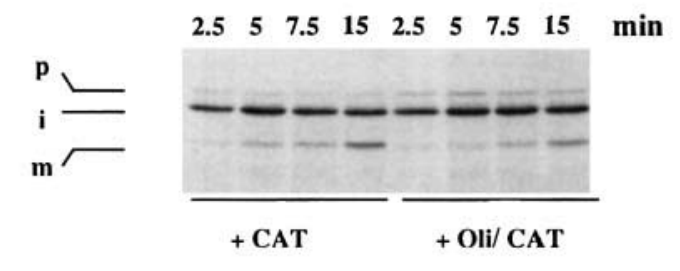

+ PK

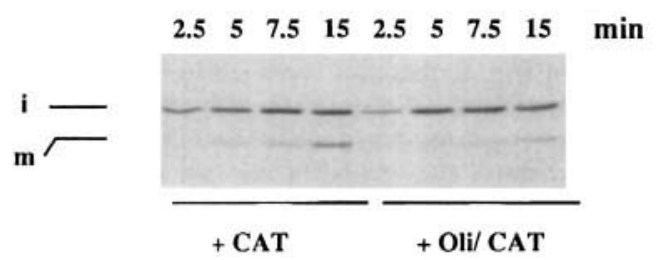

Fig. 8. Import of cytochrome $b_{2}(\Delta 135-226)$ is not inhibited by reduction of matrix-ATP levels. The cytochrome $b_{2}(\Delta 135-226)$ precursor protein was transcribed and translated in reticulocyte lysate in the presence of $\left[{ }^{35} \mathrm{~S}\right]$ methionine. The import of the precursor into control mitochondria (lanes 1-4) or ATP-depleted mitochondria (lanes $5-8 ; 40 \mu \mathrm{g}$ protein $/ 200 \mu \mathrm{l}$ sample) was performed as described in the legend of Fig. 2 at $25^{\circ} \mathrm{C}$ for the times indicated. Following import, samples were placed on ice, one half of each sample was treated with proteinase $\mathrm{K}(+\mathrm{PK})$ and the other half was mock-treated (-PK). Samples were processed as described in the Experimental Procedures section. MPP, matrix-processing peptidase; IMP1, inner-membrane protease 1; CAT, carboxyatractyloside; Oli, oligomycin; $p$, precursor; $i$, intermediate, $m$, mature.

protease 1 processing requires the presence of either a correctly folded heme-binding domain or else the presence of a bound heme group.

\section{DISCUSSION}

\section{The roles of ATP/mt-Hsp70 in translocation of the matrix-targeted precursors across the inner membrane}

Hydrolysis of matrix ATP has been proposed to constitute (at least part of) the driving force for the vectorial movement of precursors into the mitochondrial matrix. To obtain a better understanding of this complex process, we have manipulated the matrix-ATP levels. A decisive role of matrix ATP in protein import appears to be through its facilitating the reversible binding of $\mathrm{mt}-\mathrm{Hsp} 70$ to incoming polypeptide chains. This notion is supported by the observation that the effects of matrix-ATP depletion on the import of various preproteins described in this study, are directly paralleled by the effects of inactivating the mt-Hsp70 in a temperature-sensi- tive mutant (ssc1-3), which represents a tighter allele than the previously studied ssc1-2 allele [7] ([49], Stuart, R. A. and Neupert, W., unpublished results). The measured ATP levels in the matrix are fully consistent with the cooperation of mt-Hsp70 and ATP in the transfer of preproteins across the two membranes.

Results presented in this study suggest that matrix-preproteins require ATP/mt-Hsp70 for (at least) two steps in the import process. First, matrix ATP and mt-Hsp70 are involved in the translocation of the mitochondrial targeting signals across the inner membrane in conjunction with the membrane potential $\Delta \Psi$. We propose that $\Delta \Psi$ promotes the transfer of the matrix-targeting signal so that the equilibrium distribution is shifted to the matrix side of the inner membrane. However, this transfer is generally not sufficient to allow efficient processing by matrix-processing peptidase, rather mt-Hsp70/ATP, by binding to $\mathrm{N}$-terminal segments of the preprotein, drives the equilibrium further to the matrix side and thus makes the initial translocation step apparently irreversible. This suggestion is strongly supported by the observation of a novel translocation intermediate that accumulates in the presence of $\Delta \Psi$ and at very low matrix-ATP levels [46]. The second partial reaction for which ATP is required in conjunction with $\mathrm{mt}-\mathrm{Hsp} 70$ function, is the moving of the unfolded precursor polypeptides across the inner membrane, as previously proposed [9]. It appears that ATP/ mt-Hsp70 function is absolutely required for such a translocation event. Under certain ATP-depletion conditions, which are not so drastic as the ones described in this study, it appears that although inner-membrane translocation is still inhibited, some precursors can still become efficiently processed and partially translocated across the outer membrane where they accumulate in the intermembrane space as trapped intermediates [26, 47]. The efficiency of accumulation of such intermediates depends on the extent of ATP depletion and varies from precursor to precursor. The latter observation is probably connected with the folding state of the precursor, as denaturation of the precursor prior to import can increase the efficiency of accumulation of such an intermembrane-space-localized intermediate (Stuart, R. A. and Neupert, W., unpublished results).

\section{Interaction of the intermembrane space sorting signal with a recognition component enables bypass of ATP/mt-Hsp70}

In view of this sequence of events, it appears difficult to see why the import of some preproteins with bipartite signals would not require matrix ATP, nor mt-Hsp70, or at least would only show a weak dependence. This question is particularly provocative, if one compares the fusion protein $\mathrm{p} b_{2}(167)$-dihydrofolate reductase with the derivative $\mathrm{p} b_{2}(167) \Delta 19$-dihydrofolate reductase in which the intermembrane space sorting signal was inactivated by deleting 19 amino acid residues. The first construct hardly requires any matrix ATP whereas the import of the latter construct is completely inhibited under ATP depletion. The difference in ATP/Hsp70 requirement is even more striking when one considers that an exchange of a single amino acid residue in the sorting signal can lead to ATP dependent targeting to the matrix space [41]. The findings reported in this study allow us to propose a pathway that accounts for these seemingly paradoxical ATP requirements. Firstly, we suggest that in the case of precursor proteins with both an intact intermembrane space sorting signal and a mature domain which is not stabily 
folded (e.g. cytochrome- $c_{1}$-derived and cytochrome- $b_{2}$-derived fusions lacking the cytochrome $b_{5}$ domain), the ATP/ Hsp70 requirement for the translocation of the targeting signal is dispensable because a component of the sorting pathway, a sorting-signal-binding protein or particle binds to the sorting sequence. We propose that due to limited unfolding of the precursor as it inserts into the outer-membrane and inner-membrane translocation pore, the precursor can pass into the matrix to a limited extent. This reaction requires a $\Delta \Psi$ but in addition, as outlined above, to achieve a stable translocation of the N-terminal segment and to allow processing by matrix-processing peptidase, another component, usually Hsp70/ATP, is necessary. In the case of precursors with bipartite signals, this role can be exerted by the sortingsignal-binding protein. Secondly, we envisage that further translocation of these precursors into the mitochondria, at least in the absence of ATP/mt-Hsp70, can be driven by the mitochondrial export system which would transfer the precursor into the intermembrane space, preferentially in a cotranslocational manner. In the presence of ATP, mt-Hsp70 could assist in increasing the efficiency of this process, which may account for the observed stimulation of import for the aforementioned precursors in the presence of matrix ATP. In the case of the Rieske $\mathrm{Fe} / \mathrm{S}$ protein of the cytochrome $b c_{1}$ complex, there is general agreement that the precursor is completely imported into the matrix prior to its sorting to the intermembrane space $[17,22]$. This would also explain in this case why correct sorting to the intermembrane space is strongly dependent on matrix-ATP/mt-Hsp70 [7] (Fölsch, H. and Stuart, R. A., unpublished results). It appears that the extent to which an intermembrane-space-targeted precursor enters the matrix prior to initiating an export reaction can vary not only with the type of precursor but also with the kinetic conditions of the import reaction. For these reasons, one could imagine that the involvement of Hsp60 in the sorting through the matrix of intermembrane space proteins may not be obligatory and would preferentially be required under conditions which favour the accumulation of these intermediates (or segments thereof) in the matrix. Unfortunately, it is very difficult to extrapolate the abundance of matrix-localized intermediates of intermembrane space proteins found in vitro, in order to gain understanding of the situation in vivo.

It should be pointed out that the relative independence of certain intermembrane-space-targeted proteins on matrix ATP/mt-Hsp70 for import, would not depend on explaining targeting to the intermembrane space by conservative sorting. According to the stop-transfer model, one might assume that ATP-independent translocation of the targeting signal is promoted by binding of the sorting signal to a putative stoptransfer component in the inner membrane. The matrix-ATPindependent completion of translocation would then be due to a selective transfer across the outer membrane. The present data do not discriminate between these alternative views of sorting. The data do, however, exclude an interpretation using the lack of matrix-ATP requirement as a criterion in favour of stop-transfer $[18,26]$.

\section{ATP/mt-Hsp70 promotes unfolding of precursors outside the mitochondria}

Finally, we will discuss why some precursors with bipartite signals, such as precytochrome $b_{2}$, do need matrix ATP for both processing and import. Data in this study show that the matrix-ATP requirement could be largely bypassed when the precursors were unfolded prior to import. However, the requirement for matrix ATP could be relieved when segments in the mature part of the precursor were deleted that probably constitute a tightly folded domain. In agreement with previous proposals, we presume that binding of Hsp70/ATP on the matrix side can facilitate unfolding of precursors on the outside by shifting the equilibrium of the folded versus unfolded conformation. The requirement of matrix ATP and mt-Hsp70 for precytochrome $b_{2}$ import has been described previously; a deficiency in cytochrome $b_{2}$ sorting was observed in the ssc1-2 mutant in which Hsp70 (Ssc1p) was affected [7, 47]. Furthermore, it appears that in the absence of matrix ATP and mt-Hsp70 function, the cytochrome $b_{5}$ domain of cytochrome $b_{2}$ and derived fusion preproteins, is unable to unfold and thus restricts the passage of the presequence through the inner-membrane import channel to such an extent that it does not undergo processing by the matrix-processing peptidase. In this situation, the precursor accumulates as a novel translocation intermediate, which is prior to the $\Delta \Psi$-dependent import step and which can be 'chased' into the mitochondria upon re-establishment of high levels of matrix ATP [46]. In the frame of the conservative sorting model, we suggest that the driving force for export of the precursor is not sufficient to promote co-translocational transfer when unfolding of this tightly folded cytochrome $b_{5}$ domain is not mediated by mt-Hsp70 in an ATP-dependent manner. This situation would be similar to secretion in bacteria and in the endoplasmic reticulum, where export apparently is unable to drive the unfolding of completely synthesized proteins with the vast majority of precursors.

We would like to thank Sandra Weinzierl for excellent technical assistance. We are grateful to Dr Benjamin Glick for drawing our attention to the existence of the tightly folded cytochrome $b_{5}$ domain in cytochrome $b_{2}$. We thank Dr Thomas Langer for his advice regarding the ATP measurements and, together with Dr Roland Lill, for their helpful comments on the manuscript. In addition, we also thank Manfred Dünnwald for assistance with the photography. This study was supported by grants from the Sonderforschangsbereich 184, Teilprojekt B2, Fonds der Chemischen Industrie, the Münchener Medizinische Wochenschrift to R. A. S. and a long-term European Molecular Biology Organisation fellowship to I. K.

\section{REFERENCES}

1. Chen, W.-J. \& Douglas, M. G. (1987) Cell 49, 651-658.

2. Pfanner, N., Tropschug, M. \& Neupert, W. (1987) Cell 49, 815-823.

3. Deshaies, R. J., Koch, B. D., Werner-Washburne, M., Craig, E. A. \& Schekman, R., (1988) Nature 332, 800-805.

4. Schleyer, M., Schmidt, B. \& Neupert, W. (1982) Eur. J. Biochem. 125, 109-116.

5. Pfanner, N. \& Neupert, W. (1986) FEBS Lett. 209, 152-156.

6. Eilers, M., Oppliger, W. \& Schatz, G. (1987) EMBO J. 6, 1073-1077.

7. Kang, P.-J., Ostermann, J., Shilling, J., Neupert, W., Craig, E. A. \& Pfanner, N. (1990) Nature 348, 137-142.

8. Scherer, P. E., Krieg, U. C., Hwang, S. T., Vestweber, D. \& Schatz, G. (1990) EMBO. J. 9, 4315-4322.

9. Neupert, W., Hartl, F.-U., Craig, E. A. \& Pfanner, N. (1990) Cell 63, 447-450.

10. Manning-Krieg, U. C., Scherer, P. E. \& Schatz, G. (1991) EMBO J. 10, 3273-3280.

11. Ostermann, J., Horwich, A. L., Neupert, W. \& Hartl, F.-U. (1989) Nature 341, 125-130.

12. Schneider, H., Arretz, M., Wachter, E. \& Neupert, W. (1990) J. Biol. Chem. 265, 9881-9887.

13. Kaput, J., Goltz, S. \& Blobel, G. (1982) J. Biol. Chem. 257, 15054-15058. 
14. van Loon, A. P. G. M., Brändli, A. W. \& Schatz, G. (1986) Cell $44,801-812$.

15. van Loon, A. P. G. M., Brändli, A. W., Pesold-Hurt, B., Blank, D. \& Schatz, G. (1987) EMBO J. 6, 2433-2439.

16. Hurt, E. C. \& van Loon, A. P. G. M. (1986) Trends Biochem. Sci. 11, 204-207.

17. van Loon, A. P. G. M. \& Schatz, G. (1987) EMBO J. 6, $2441-$ 2448.

18. Glick, B. S., Brandt, A., Cunningham, K., Müller, S., Hallberg, R. L. \& Schatz, G. (1992) Cell 69, 809-822.

19. Glick, B. S., Beasley, E. M. \& Schatz, G. (1993) Trends Biochem. Sci. 17, 453-459.

20. Beasley, E. M., Müller, S. \& Schatz, G. (1993) EMBO J. 12, 2303-2311.

21. Hartl, F.-U. \& Neupert, W. (1990) Science 247, 930-938.

22. Hartl, F.-U., Schmidt, B., Weiss, H., Wachter, E. \& Neupert, W. (1986) Cell 47, 939-951.

23. Hartl, F. U., Ostermann, J., Guiard, B. \& Neupert, W. (1987) Cell 51, 1027-1037.

24. Guiard, B. (1985) EMBO J. 4, 3265-3272.

25. Xia, Z. \& Matthews, F. S. (1990) J. Mol. Biol. 212, 837-863.

26. Wachter, C., Schatz, G. \& Glick, B. (1992) EMBO J. II, 47874794.

27. Ostermann, J., Voos, W., Kang, P. J., Craig, E. A., Neupert. W. \& Pfanner, N. (1991) FEBS Lett. 277, 281-284.

28. Rassow, J., Hart1, F.-U., Guiard, B., Pfanner, N. \& Neupert, W. (1990) FEBS Lett. 275, 190-194.

29. Stuart, R. A., Nicholson, D. W. \& Neupert, W. (1990a) Cell 60 , $31-43$.

30. Stuart, R. A., Nicholson, D. W., Wienhues, U. \& Neupert, W. (1990b) J. Biol. Chem. 265, 20210-20219.

31. Wienhues, U., Koll, H., Becker, K., Guiard, B. \& Hartl, F.-U. (1992) A practical approach to protein targeting, IRL Press Ltd, Oxford University Press.
32. Daum, G., Gasser, S. M. \& Schatz, G. (1982) J. Biol. Chem. 257, 13075-13080.

33. Krieg, P. A. \& Melton, D. A. (1984) Nucleic Acids Res. 12, $7057-7070$.

34. Pelham, H. R. B. \& Jackson, R. J. (1976) Eur. J. Biochem. 67, $247-256$

35. Zimmermann, R. \& Neupert, W. (1980) Eur. J. Biochem. 109, $217-229$

36. Bradford, M. M. (1976) Anal. Biochem. 72, 248-254.

37. Laemmli, V. K. (1970) Nature 227, 680-685.

38. Maniatis, T., Fritsch, E. F. \& Sambrook, J. (1982) Molecular cloning: a laboratory manual, 2nd edn, Cold Spring Harbor Laboratory, Cold Spring Harbor, NY.

39. Ohnishi, T., Kröger, A., Heldt, H. W., Pfaff, E. \& Klingenberg, M. (1967) Eur. J. Biochem. 1, 301-311.

40. Koll, H., Guiard, B., Rassow, J., Ostermann, J., Horwich, A. L., Neupert, W. \& Hartl, F.-U. (1992) Cell 68, 1163-1175.

41. Schwarz, E., Seytter, T., Guiard, B. \& Neupert, W. (1993) EMBO J. 12, 2295-2302.

42. Liberek, K., Marszalek, J., Ang, D., Georgopoulos, L. \& Zylicz, M. (1991) Proc. Natl Acad. Sci. USA 8, 2874-2878.

43. Cross, R. L. \& Nalin, C. M. (1982) J. Biol. Chem. 257, 28742881.

44. Rott, R. \& Nelson, N. (1981) J. Biol. Chem. 256, 9224-9228.

45. Schneider, A., Behrens, M., Scherer, P. E., Pratje, E., Michaelis, G. \& Schatz, G. (1991) EMBO J. 10, 247-254.

46. Cyr, D. M., Stuart, R. A. \& Neupert, W. (1993) J. Biol. Chem. $268,23751-23754$.

47. Hwang, S. T. \& Schatz, G. (1989) Proc. Natl Acad. Sci. USA $86,8432-8436$.

48. de Wet, J. R., Wood, K. V., deLuca, M., Helinski, D. R. \& Subramani, S. (1987) Mol. Cell. Biol. 7, 725-737.

49. Voos, W., Gambill, B. D., Guiard, B., Pfanner, N. \& Craig, E. A. (1993) J. Cell. Biol. 123, 109-118. 